\title{
Community Pharmacists' Knowledge and Attitudes Towards Pediatric Pain Management in Nigeria
}

\author{
ibrahim Ogunyinka, (D) \\ Kazeem Yusuff, ${ }^{2}$ Patrick O Erah, ${ }^{3}$ \\ Kazeem Oshikoya, ${ }^{4}$ \\ Folayemi Faponle, ${ }^{5}$ Hussein Ungo- \\ kore, ${ }^{6}$ Ibrahim Oreagba, ${ }^{7}$ \\ Ahmed Yakasai, ${ }^{8}$ Anthony Idoko, \\ Solape lleoma, ${ }^{10}$ Aminu Umar ${ }^{1}$ \\ 'Department of Clinical Pharmacy and \\ Pharmacy Practice, Faculty of \\ Pharmaceutical Sciences, Usmanu Danfodiyo \\ University Sokoto, Sokoto, Nigeria; \\ ${ }^{2}$ Department of Clinical Pharmacy and \\ Practice, College of Pharmacy, QU Health, \\ Qatar University, Doha, Qatar; \\ ${ }^{3}$ Department of Clinical Pharmacy and \\ Pharmacy Practice, Faculty of Pharmacy, \\ University of Benin, Benin City, Nigeria; \\ ${ }^{4}$ Department of Pharmacology, \\ Therapeutics and Toxicology, College of \\ Medicine, Lagos State University, lkeja, \\ Lagos, Nigeria; ${ }^{5}$ Department of Anaesthesia \\ and Intensive Care Unit, Faculty of Clinical \\ Sciences, College of Health Sciences, \\ Obafemi Awolowo University, lle-lfe, Osun \\ State, Nigeria; ${ }^{6}$ Department of \\ Pharmaceutics and Pharmaceutical \\ Microbiology, Faculty of Pharmaceutical \\ Sciences, Usmanu Danfodiyo University \\ Sokoto, Sokoto, Nigeria; ${ }^{7}$ Department of \\ Pharmacology, Therapeutics and Toxicology, \\ College of Medicine, University of Lagos, Idi- \\ Araba, Lagos, Nigeria; ${ }^{8}$ Pharmaplus Nigeria \\ Limited, Kano, Nigeria; ${ }^{9}$ Directorate of \\ Education and Training, Pharmacists Council \\ of Nigeria, Idu, Abuja, Nigeria; ${ }^{10}$ Department \\ of Pharmacy, Lagos Island Maternity \\ Hospital, Lagos, Nigeria
}

Correspondence: ibrahim Ogunyinka Department of Clinical Pharmacy and Pharmacy Practice, Usmanu Danfodiyo University Sokoto, Sokoto, PMB 2346, Nigeria

Tel +234-803-936-3848

Email ibl072000@yahoo.com.au
Purpose: Community pharmacists (CPs) frequently attend to pediatric patients with pain but limited data exist regarding their knowledge of and attitude to effective management of pediatric pain in Nigeria. Thus, this study aimed to evaluate the knowledge of and attitude to pediatric pain management among CPs in Nigeria.

Patients and Methods: A validated and pilot-tested questionnaire, the Community Pharmacists Survey on Pediatric Pain, was administered to 517 eligible participants at the 38th Annual National Conference of the Association of Community Pharmacists of Nigeria. Independent samples $t$-test and one-way analysis of variance were used for inferential statistical analyses.

Results: CPs with additional higher academic qualifications and clinically related additional academic degrees had significantly higher mean knowledge scores relative to first degree only holder counterpart $\left(\mathrm{t}=4.33, \mathrm{p}<0.05, \mathrm{Eta}^{2}=0.05\right)$ and those without clinically related second degrees $\left(\mathrm{t}=6.34, \mathrm{p}<0.05, \mathrm{Eta}^{2}=0.27\right)$. Pain knowledge among the study cohort also varied significantly by age group, years of practicing community pharmacy, ownership structure of premises, geographical location of practice and previous exposure to pain management training $(\mathrm{F}(4370)=2.858, \mathrm{p}=0.025$, $\mathrm{Eta}^{2}=0.03 ; \mathrm{F}(3371)=3.985, \mathrm{p}=0.008, \mathrm{Eta}^{2}=0.03 ; \mathrm{F}(2372)=3.643, \mathrm{p}=0.027, \mathrm{Eta}^{2}=0.02 ; \mathrm{F}(5369)$ $\left.=4.497, \mathrm{p}=0.01, \mathrm{Eta}^{2}=0.06 ; \mathrm{F}(2372)=3.587, \mathrm{p}=0.029, \mathrm{Eta}^{2}=0.02\right)$, respectively.

Conclusion: Community pharmacists' knowledge of and attitude to pediatric pain management in Nigeria appeared sub-optimal, and requires regular targeted educational intervention to fill the identified gaps, improve service delivery and patient outcomes.

Keywords: conference, pain location, questionnaire, referrals

\section{Plain Language Summary}

Pain is a common sign of many ailments and diseases and community pharmacists are often the first port of call for the management of such diseases. Consequently, community pharmacists frequently attend to children with pain in their premises. However, limited data exists regarding the knowledge of such community pharmacists. Therefore, we conducted a survey among 517 community pharmacists during the 38th Annual National Conference of the Association of Community Pharmacists of Nigeria in 2019 to assess their knowledge of pediatric pain management.

Community pharmacists' knowledge and attitude towards managing children with pain was found to be associated with having additional and clinically related higher academic degrees. Similarly, this association was also found for those who have had a previous pain management training, commenced practice within the last decade and are employees.

We concluded that community pharmacists' knowledge and attitude towards managing children with pain in Nigeria is sub-optimal, and recommended tailored educational interventions such as pharmacy education curriculum modification where more time be allotted to pain management right from the undergraduate level and during the Mandatory Continuous 
Professional Development Program conducted by Pharmacists Council of Nigeria. We also recommend regular training and retraining of healthcare professionals across the country by relevant stakeholders such as Federal Ministry of Health.

Lastly, this survey revealed sub-optimal pediatric pain knowledge among the surveyed community pharmacists and this can impact how well children with pain are being managed. Knowing that undertreated pain in childhood has future adverse consequences underscores the importance of this survey finding.

\section{Introduction}

Pain is a subjective and non-discriminating phenomenon that can be defined as an unpleasant sensory and emotional experience associated with, or resembling that associated with, actual or potential tissue damage. ${ }^{1}$ Pain has also been recognized as a complex multidimensional experience involving the interaction of biological, psychological and social factors of the sufferer. ${ }^{2}$ Children with acute, chronic and neuropathic pain frequently present to healthcare settings including community pharmacies with the prevalence of those with chronic pain estimated to be between $20 \%$ and $35 \%$ worldwide. ${ }^{3-5}$ The economic burden of pediatric pain has not been adequately described in Nigeria. However, in resource-rich settings such as the United Kingdom, the cost of treating chronic pain in adolescents is estimated at $£ 3.8$ billion annually, ${ }^{6}$ and $\$$ 19.5 billion per annum in the United States. ${ }^{7}$

Pain is the commonest reason for seeking the services of community pharmacists (CPs), making them an important component of the pain care continuum..$^{8-10}$ Despite this high prevalence, pediatric pain continues to be underdiagnosed, and undertreated, ${ }^{11-15}$ and poor knowledge of healthcare providers (HCPs) about comprehensive pain management is one of the reasons identified. ${ }^{9,10,16-23}$ In order to address the "treatment gap" or "evidence-practice gap", 24,25 the Federal Ministry of Health (FMOH), Nigeria in collaboration with the American Cancer Society launched a program, Pain-Free Hospital Initiative (PFHI) in 2015 and trained over 11,000 HCPs including doctors, pharmacists, nurses and physiotherapists across 14 federal tertiary hospitals over a one-year period in order to integrate effective pain treatment into hospital-based service. ${ }^{26}$ However, this laudable initiative excluded community pharmacists. The Ministry went further in 2018 to launch the Guidelines for pain management in Nigeria, which considers pain management approach as interdisciplinary, patient-focused and recognizes the crucial role of pharmacists as pain care providers. $^{26}$
Analgesics are the cornerstone of pain pharmacotherapy with over-the-counter (OTC) analgesics representing the largest market of OTC drug sales worldwide. ${ }^{27}$ However, studies have shown that pain management in pediatric patients is inadequate and associated with negative short-term consequences including prolonging hospitalization, poor quality of life and carrying significant cost to society, ${ }^{28,29}$ and longterm consequences such as poorer cognition and motor function, increased risk of developing chronic pain in adulthood and future avoidance of healthcare. ${ }^{30-35}$ Therefore, regular audit of pediatric pain management including assessment of the adequacy of the knowledge of the HCPs is warranted and could lead to the identification gaps that require intervention for improvement.

Moreover, previous studies on pain management involving pharmacists are few, mostly hospital-based and focused on adults with pain. ${ }^{19,21,36,37}$ Fewer studies still have involved community pharmacists but none has focused on pediatric pain. ${ }^{9,38,39}$ Hence, findings from the current study could provide new perspective that could add significantly to existing global knowledge in the research area. In addition, community pharmacists are Frontline healthcare professionals that are easily accessible especially at the primary care level and could contribute significantly to the effective management of pediatric pain in Nigeria. Thus, this study was undertaken to evaluate CPs' knowledge of and attitude to pediatric pain management in Nigeria.

\section{Materials and Methods Design and Setting}

This was a cross-sectional, descriptive survey involving a purposive sampling of $517 \mathrm{CPs}$. The sampling frame included all the community pharmacists (623) who attended the 38th Annual National Conference of the Association of Community Pharmacists of Nigeria (ACPN) that took place in Kano state, Nigeria between June 30, 2019 and July 6, 2019. The conference was the largest gathering of CPs in Nigeria and had attendees from the six geopolitical zones in Nigeria. Although 517 CPs agreed to participate in the study, however, only the data of 375 CPs were evaluated as per the study protocol.

\section{Questionnaire Development and Validation}

The questionnaire, community pharmacists survey on pediatric pain (CPSPP), comprised 40 items with three components-demographic characteristics, knowledge and 
practice was developed after a thorough review of relevant literature. $^{20,23,40-46}$ The knowledge and attitude components were divided into four domains: multidimensional nature of pain, pain assessment and measurement, management of pain and clinical conditions; based on the IASP curriculum. These four domains of have been validated by Fishman et al. ${ }^{47}$

The psychometric evaluation of the knowledge component of CPSPP (which had 35 initial items identified after literature review) consisted of two phases. The first phase involved face and content validity assessment of the knowledge components of the questionnaire by a 7-member panel with expertise in pediatric pain management. The panel comprised of consultant anesthetist, clinical pharmacologists and pediatrician. It also included pharmacists who practice in the community, hospital and academia; and a registered senior nurse. The copy sent to the experts had a 5-point scale (varying from 1-not relevant to 5 -very relevant) against each of the 35 items and space was also provided for comments such as reasons for the respective scores and suggestions for each item. The first phase resulted in the reduction of the knowledge component of the questionnaire items to 24 items with several modifications including rephrasing and reordering. For the second phase, which also served as pilot testing of CPSPP; the 24 knowledge and attitude items were administered to $23 \mathrm{CPs}$ and this process was repeated after two weeks using the same version of CPSPP and group of 23 CPs. The result of reliability analysis via test-retest and the Cronbach's alpha were 0.738 and 0.715 , respectively.

The final version of the 42-item CPSPP had 9 items for demographics, 24 and 9 items, respectively, for knowledge and attitude, and practice of pediatric pain management. The demographics include questions relating to age, gender, highest qualification including degrees earned, years of qualification, years of practice as a community pharmacist, previous area of practice (and if yes, where), ownership and geopolitical zone location of the premises. The degrees include first degree such as Bachelor of Pharmacy, while second or third degree were sub-divided into clinically related and non-clinically related degrees. Clinically related degrees include Doctor of Pharmacy (Pharm D), Fellowship of West African Postgraduate College of Pharmacists, Masters in Clinical Pharmacy, Pharmacology, Pharmacoeconomics, Pharmaceutical Microbiology, Pharmaceutics, and Public Health; and $\mathrm{PhD}$ in Pharmacology. Non-clinically related degrees include Masters in Business Administration and Gender
Studies, Postgraduate Diploma in Education and Bachelor of Law.

The knowledge and attitude items covered 4 pain domains: multidimensional nature of pain, pain assessment and measurement, management of pain, clinical conditions/pain syndromes. The practice items covered issues like previous recipient of pain management training, number of such trainings attended and by whom, location and perceived cause of pain encountered in practice, painful conditions ever referred and what influenced the referral and interest in future training whether previously trained or not. Of the 24 items on knowledge, 11 items were assessed on a 3-point Likert scale (Yes, I agree; I am not sure and No, I disagree). The responses to the 11 items were taken as an indicator of knowledge and were categorized into correct, incorrect or unsure answers. ${ }^{23}$ The remaining 13 items with multiple-choice responses were categorized into a 3-answer format: correct, incorrect and unsure with responses closely related to the correct answer categorized as incorrect and those unrelated to the correct response as unsure. For instance, item 13: adjuvant is an unrelated response while non-opioids and strong opioids are closely related responses to the correct response (weak opioids). The responses to the 24 items were taken as an indicator of knowledge and were categorized into correct, incorrect or unsure answers. ${ }^{23}$ For each participant, the raw number of correct, incorrect and unsure answers were scored (Table 1). Correct answers were based on the criteria of pain therapy from Guidelines for the management of pain in Nigeria, ${ }^{26}$ Pediatric Nurses' Knowledge and Attitude Survey (PNKAS-Shriners Revision), ${ }^{48}$ and previous studies. ${ }^{23,44-46}$ Items related to knowledge and attitude were analyzed as a single concept in accordance with previous studies. ${ }^{23,49}$

\section{Participants}

The study participants (517) were those who met the study eligibility criteria such as attending the ACPN national conference, being registered members of ACPN and have attended to children with pain in the last 6 months. However, only the data of 357 ( $70 \%$ males, $30 \%$ females) respondents who completed the 24 questions/items assessing the knowledge and attitude of pediatric pain were analyzed.

\section{Procedure for Data Collection}

CPSPP was administered to the 623 eligible CPs who were invited to participate in the study and only 517 completed the questionnaire. However, only the data of $375 \mathrm{CPs}$ (out of 


\begin{tabular}{|c|c|c|c|c|c|c|c|c|c|c|c|c|c|c|c|c|c|c|}
\hline 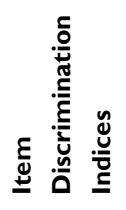 & $\stackrel{0}{0}$ & $\frac{\circ}{0}$ & $\stackrel{\text { O̊. }}{0}$ & $\stackrel{\circ}{\circ}$ & 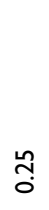 & $\frac{\sigma}{0}$ & 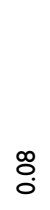 & $\bar{o}$ & $\bar{O}$ & @̊ & $\bar{o}$ & f́. & $\stackrel{\infty}{0}$ & $\bar{ָ}$ & $\frac{T}{0}$ & $\stackrel{\infty}{0}$ & ઼ָ & $\stackrel{\circ}{\circ}$ \\
\hline E & $\begin{array}{l}\infty \\
\stackrel{\infty}{\circ}\end{array}$ & $\stackrel{\text { นn }}{0}$ & $\stackrel{0}{0}$ & f. & б. & ઼ָ & 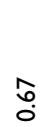 & 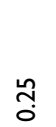 & Ŝ & f̊. & ઼ָָ & గิ તૂ & $\stackrel{1}{0}$ & $\stackrel{\infty}{\infty}$ & $\stackrel{\circ}{\circ}$ & $\stackrel{\circ}{\circ}$ & $\frac{m}{0}$ & 응 \\
\hline
\end{tabular}

\section{गัญ}

$\frac{n}{4}$

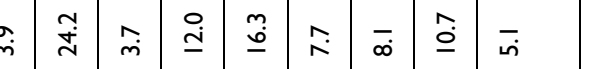

$\sigma$.

$\stackrel{n}{i}$

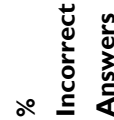

过

일

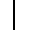

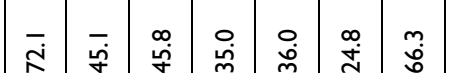

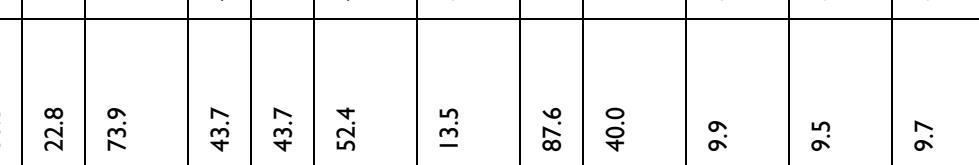

\section{苞}

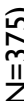

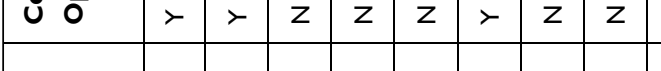

is

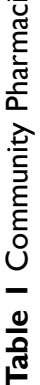

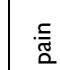

$\frac{0}{0.0}$

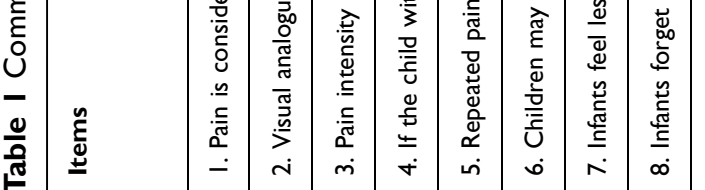

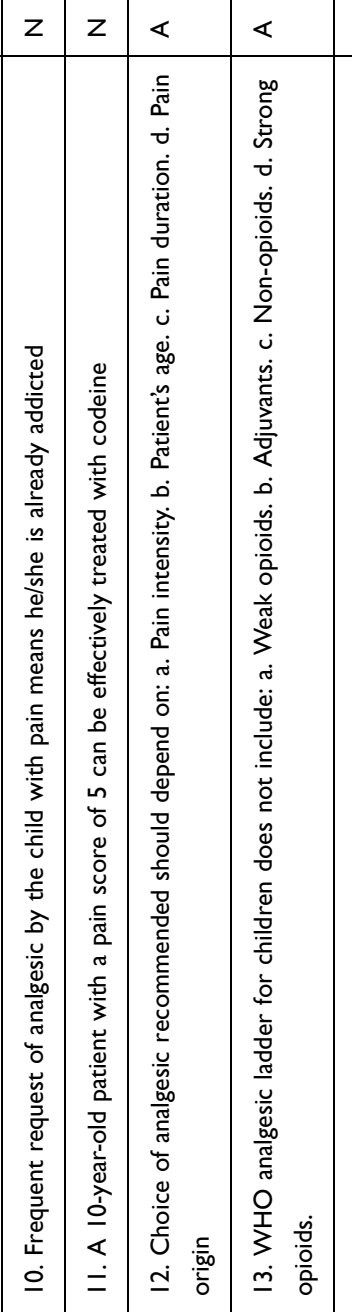

$\circ$

$\begin{array}{lll}0 & 0 & 0\end{array}$

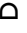

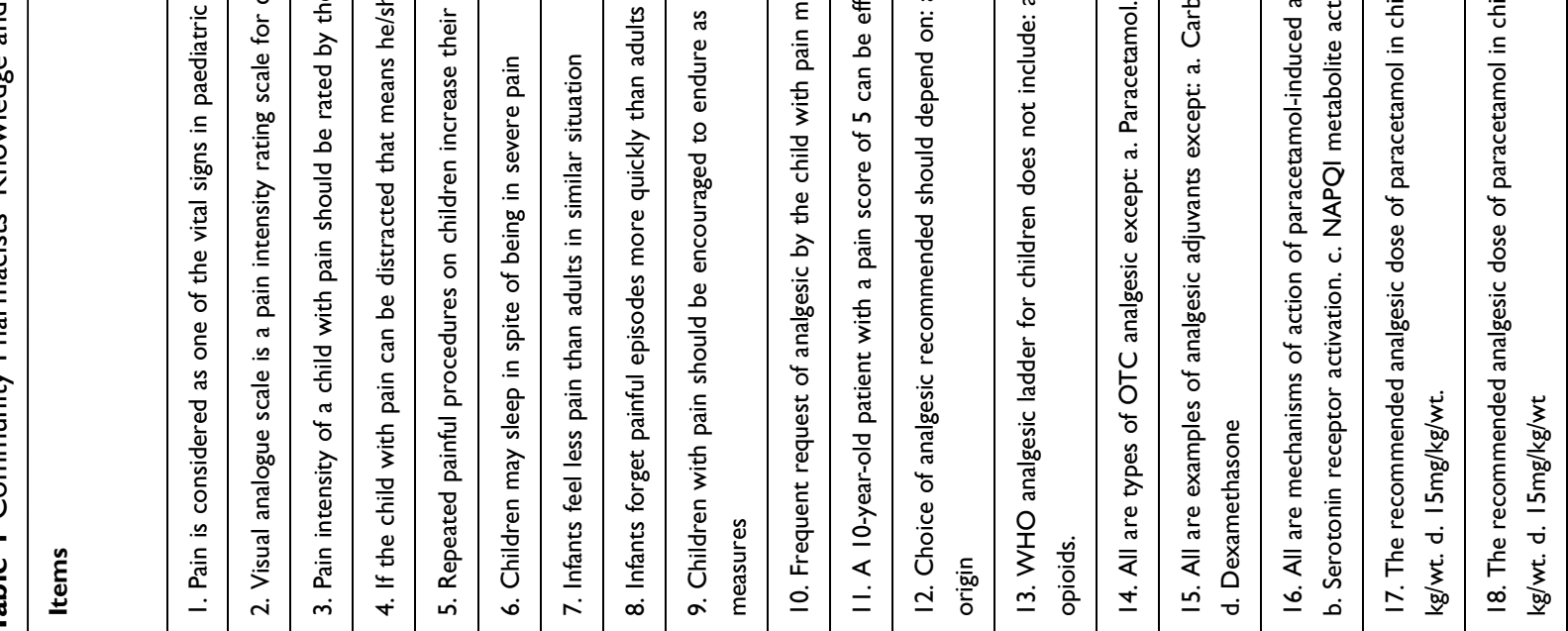




\begin{tabular}{|c|c|c|c|c|c|c|}
\hline$\overline{\check{~}}$ & f̃. & চ̋ & চ̋ & స్రి & 迆 & \\
\hline ণ্ণి & $\begin{array}{l}\stackrel{n}{0} \\
\stackrel{0}{0}\end{array}$ & : & กิ & ণ্ণি & 華 & \\
\hline$\stackrel{m}{\sim}$ & $\stackrel{m}{m}$ & $\cong$ & $\bar{m}$ & $\stackrel{\sim}{\mathrm{N}}$ & $\bar{m}$ & 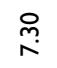 \\
\hline 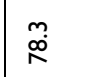 & 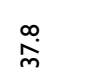 & $\begin{array}{l}n \\
\stackrel{n}{0}\end{array}$ & $\underset{\mathfrak{H}}{\tilde{y}}$ & 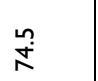 & $\underset{\mathscr{H}}{\tilde{y}}$ & 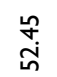 \\
\hline$\stackrel{\check{\perp}}{\Perp}$ & 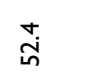 & 菅 & f & $\stackrel{\circ}{\tilde{j}^{j}}$ & fُ & 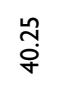 \\
\hline ○ & $u$ & ه & ○ & ه & ه & \\
\hline 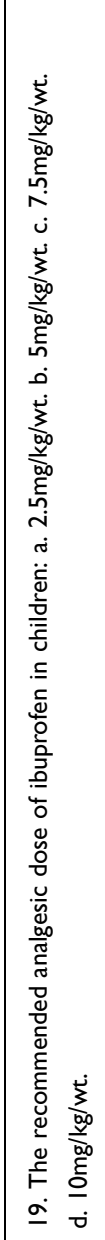 & 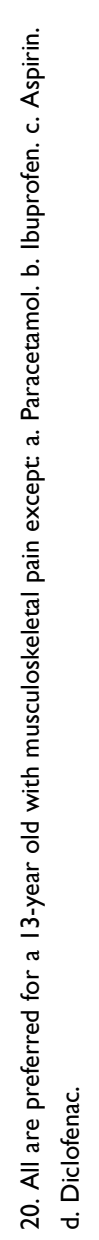 & 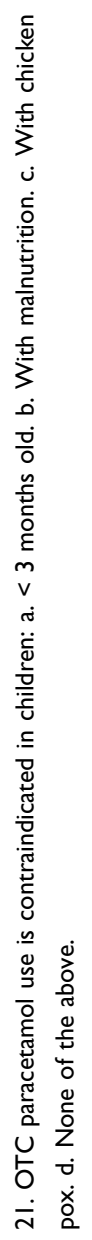 & 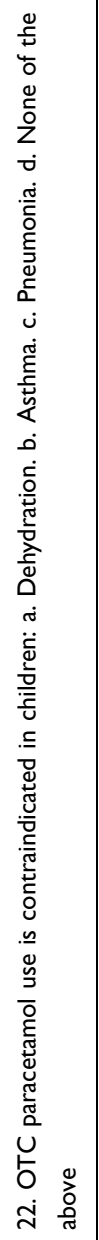 & 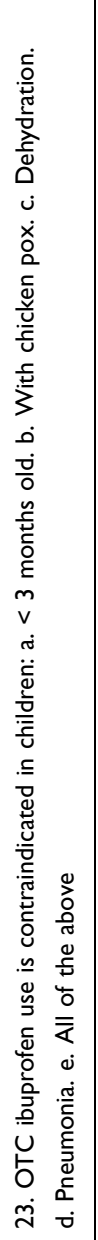 & 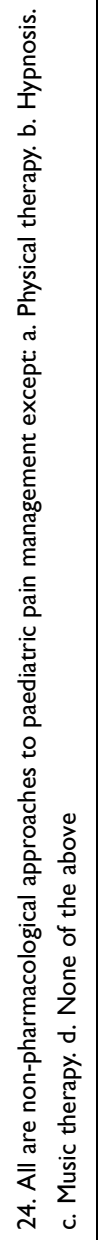 & $\begin{array}{l}\vec{\leftarrow} \\
\stackrel{\leftarrow}{O}\end{array}$ \\
\hline
\end{tabular}

$517 \mathrm{CPs}$ ) who completely filled the 24 items on knowledge and attitude were analyzed. The introductory part of the questionnaire provided participants with information on study aim and objectives, that participation was voluntary and they were all assured of the confidential handling of the information provided. Participants' consent was sought with the following statement and a Yes- and No- box: "Please tick $(\sqrt{ })$ the Yes-box if you agree to take part in this study".

\section{Data Analysis}

Data were analyzed using IBM SPSS statistics software, version 25.0 (IBM Corporation, Armonk, NY, USA: released 2017). The knowledge and attitude data were tested for normality with the Shapiro-Wilk test $(\mathrm{p}>0.05)$. The demographic profile and data related to pediatric pain management were described with frequencies and proportions. Correct, incorrect and unsure answers were calculated for each knowledge item. Cronbach $\alpha$, intra-class correlation coefficient (ICC), item difficulty and discrimination indices were used to evaluate the psychometric properties of CPSPP. A $t$-test for independent samples was used to examine the differences in knowledge scores between male and female participants, those with additional academic qualifications - including clinically related vs non-clinically related degrees and those who ever referred encountered painful episodes vs those who did not. Further, one-way between-group analysis of variance (ANOVA) was used to determine whether knowledge score levels differed by age groups, type of practice before entry into community pharmacy practice, years of practice in community pharmacy, geographical location and ownership structure of the practice. Following the univariate analyses, associations and relationships with $p$ values $\leq 0.05$ were considered significant and their effect sizes were determined using Eta squared-0.01 (small effect); 0.06 (moderate effect); 0.14 (large effect). ${ }^{50}$

\section{Results}

\section{Demographic Profiles and Referral Practices of the Participants}

The response and completion rates were 83.0\% (517/623) and $72.5 \%$ (375/517), respectively. Most of the participants are aged $40-49$ years $(29 \% ; 110 / 375)$, selfemployed $(61 \% ; 227 / 375)$, commenced practicing in the hospital $(64 \% ; 163 / 255)$ before venturing into community pharmacy practice within the last 10 years $(53 \%$; 199/375) and practicing in the Northwestern part of Nigeria $\{32 \%$; $121 / 375\}$ (Table 2). Referral of painful episodes encountered was done by $68 \%(255 / 375)$ of participants and 
mostly (47\%; 96/203) for patients/clients to access better care. The participant-reported perceived causes of pediatric pain encountered were mostly due to diseases $(51 \%$; $168 / 327)$ such as arthritis $(15 \% ; 25 / 168)$, infections $(25 \%$; $42 / 168)$, and sickle cell $(23 \% ; 39 / 168)$ (Table 2). Majority $(71 \% ; n=266)$ of the participants had Bachelor of Pharmacy degree as their highest academic qualification and those with two or more second degrees had the highest percentage of correct answers $(45.2 \%)$ and lowest percentages of incorrect (39.3\%) and unsure answers (15.6\%) regarding the knowledge component of CPSPP (Figure 1). However, these differences in knowledge of pediatric pain management were not statistically significant $(\mathrm{F}(2372)=0.965, p=0.382)$. The part of the body most

Table 2 Sociodemographic Characteristics of the Participants Who Responded to Community Pharmacists Survey on Pediatric Pain Management in Nigeria $(\mathrm{N}=375)$

\begin{tabular}{|l|l|}
\hline Characteristics & Frequency $\mathbf{n}(\%)$ \\
\hline Gender & \\
Male & $262(70.0)$ \\
Female & $113(30.0)$ \\
\hline Age group (years) & \\
$20-39$ & $52(14)$ \\
$30-39$ & $99(26)$ \\
$40-49$ & $110(29)$ \\
$50-59$ & $65(17)$ \\
$\geq 60$ & $49(13)$ \\
\hline Years of qualification & \\
I-10 & $145(39)$ \\
II-20 & $10(27)$ \\
2 I-30 & $77(21)$ \\
3 I-40 & $42(11)$ \\
$\geq 4 I$ & $11(3)$ \\
\hline Years of practice & \\
I-10 & $199(53)$ \\
II-20 & $84(22)$ \\
2 I-30 & $60(16)$ \\
3 I-40 & $32(9)$ \\
\hline Previous area of practice & \\
Yes & $255(68)$ \\
No & $120(32)$ \\
\hline Areas previously practiced & $171(67.1 \%)$ \\
Hospital & $63(25)$ \\
Industrial & $21(8)$ \\
\hline & \\
\hline & \\
\hline
\end{tabular}

(Continued)
Table 2 (Continued).

\begin{tabular}{|c|c|}
\hline Characteristics & Frequency n (\%) \\
\hline \multicolumn{2}{|l|}{ Ownership structure } \\
\hline Self-owned & $227(6 I)$ \\
\hline Co-owned & $33(9)$ \\
\hline Employed & $115(31)$ \\
\hline \multicolumn{2}{|l|}{ Geopolitical zone of practice } \\
\hline Northcentral & $84(22)$ \\
\hline Northeast & $24(6)$ \\
\hline Northwest & $12 \mid(32)$ \\
\hline Southeast & $15(4)$ \\
\hline Southsouth & $59(16)$ \\
\hline Southwest & $72(19)$ \\
\hline \multicolumn{2}{|l|}{ Ever trained on pain management } \\
\hline Yes & $182(49)$ \\
\hline No & $170(45)$ \\
\hline Cannot remember & $23(6)$ \\
\hline \multicolumn{2}{|l|}{ Frequency of training on pediatric pain } \\
\hline Once & 143 (79) \\
\hline Twice & $27(15)$ \\
\hline Thrice & $12(7)$ \\
\hline \multicolumn{2}{|l|}{ Ever referred on pediatric pain } \\
\hline Yes & $255(68)$ \\
\hline No & $120(32)$ \\
\hline \multicolumn{2}{|l|}{ Reasons for referral } \\
\hline Pain intensity & $45(22)$ \\
\hline Urgent care & $16(8)$ \\
\hline Better care & $96(47)$ \\
\hline Not responding to OTC analgesics & $29(14)$ \\
\hline Pain etiology determination & $17(8)$ \\
\hline \multicolumn{2}{|l|}{ Perceived cause of pain } \\
\hline${ }^{\mathrm{a}}$ Disease-related & $168(5 \mathrm{I})$ \\
\hline bSocial event-related & $94(29)$ \\
\hline Menstruation & $13(4)$ \\
\hline Unknown & $52(16)$ \\
\hline
\end{tabular}

Notes: ${ }^{2}$ Disease-related: Arthritis-25, Cancer-7, Ulcer-10, Neuropathy-19, Infections42 (Malaria-12, Bacterial infections-25, Dental abscess-3, Toothache-2), Sickle cell disease-39, Burns-7, Asthma-3, Appendicitis-3, Circumcision-I, Surgery-3, Diabetes (Diabetic foot)-3, Hernia-6; ' 'Social event-related: Home (Falls (8), Fights (20), Domestic accidents such as knife cuts-2), Road traffic accidents-49, Sports- 15.

Abbreviations: Hosp, Hospital; Ind, Industrial; Pharma, Pharmacy.

frequently associated with pediatric pain was neck/ shoulder $(27.6 \% ; 56 / 203)$, followed by generalized/nonlocalized $(20.2 \% ; 41 / 203)$ and limb $(19.7 \% ; 40 / 203)$. Participating CPs from the Northeastern part of Nigeria had the highest proportion of correct answers (45\%) and were closely followed by those practicing in both Northwestern and Southeastern Nigeria (43\%). 


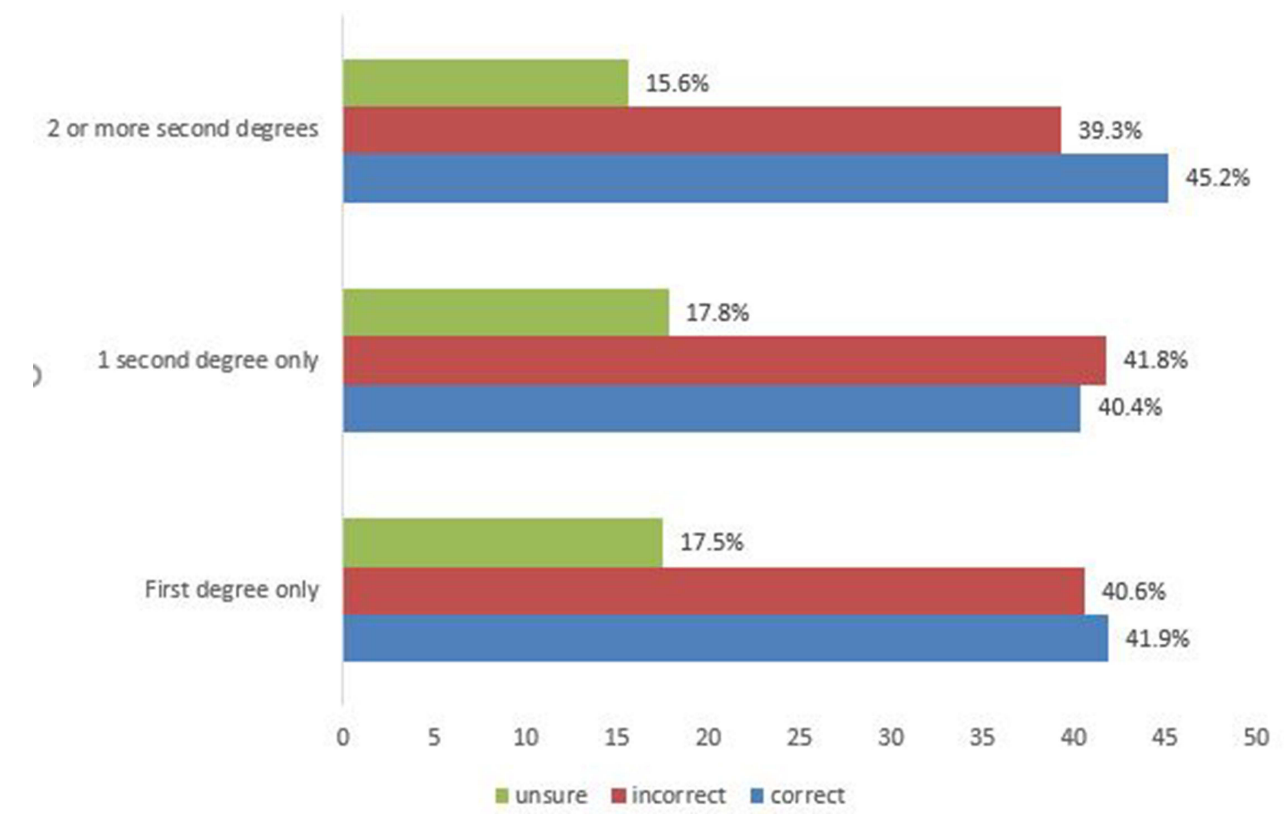

Figure I Percentage of correct, incorrect and unsure answers by highest academic qualifications of the 375 participating community pharmacist.

Notes: First degree-Bachelor of Pharmacy-266; I second degree-90: Doctor of Pharmacy (Pharm D)-5; Fellowship of West African Postgraduate College of Pharmacists-24; Master in Clinical Pharmacy-I I; Master in Pharmacology-6; Master in Public Health-4; Master in Pharmacoeconomics-2; Master in Pharmaceutical Microbiology-5; Master in Pharmaceutics/Pharmaceutical Technology-8; Master in Business Administration-15; Master in Gender Studies-3; Postgraduate Diploma in Education-4; Bachelor of Law-3 2 or more second degrees-19: 2 second degrees-8: Master in Pharmacology + Fellowship of West African Postgraduate College of Pharmacists-3; Master in Public Health + Fellowship of West African Postgraduate College of Pharmacists-3; Master in Business Administration + Fellowship of West African Postgraduate College of Pharmacists-2 3 second degrees-6: Master in Clinical Pharmacy + Fellowship of West African Postgraduate College of Pharmacists + Master in Business Administration-3; Master in Pharmacology + Fellowship of West African Postgraduate College of Pharmacists + Master in Business Administration-3. Third degree-2: Ph D in Pharmacology-2. Ph D in Pharmacology + Pharm D-3.

\section{Psychometric Properties of the Questionnaire}

The knowledge and attitude items of the CPSPP demonstrated good reliability $(\alpha=0.681$; ICC $=0.693)$. The Item Difficulty Indices ranged from 0.05 (item 18 ) to 0.86 (item 14). Almost all the items had their Difficulty Indices within the optimal level (0.2-0.8) except for items 13, 14-18 (Table 1). ${ }^{51}$ The Item Discrimination Indices also ranged from 0.01 (items $8,9,11$ ) to 0.61 (items 21, 22).

\section{Knowledge of and Attitude to Pediatric Pain Management}

The mean correct answers were significantly higher for male CPs relative to female CPs $(10.06 \pm 5.19\{41.9 \%\}$ vs $\left.9.90 \pm 6.13\{41.3 \%\} ; \mathrm{t}=4.98, p<0.05, \mathrm{Eta}^{2}=0.06\right)$, while the mean of incorrect answers was significantly lower for male participants $(9.78 \pm 4.20\{40.8 \%\})$ relative to females $(9.82 \pm 4.98\{40.9 \%\})(\mathrm{t}=-5.90, p<0.05$, $\mathrm{Eta}^{2}=0.09$ ) (Table 3). Table 3 also shows the performance of $\mathrm{CPs}$ in relation to their additional academic qualifications, the type of second degrees earned, having practiced in other areas of the profession before venturing into community pharmacy practice and knowing the cause of the painful episodes encountered. However, in terms of practice of pediatric pain management, referral practice was not significantly associated with knowledge of pediatric pain management. Those who reported not ever referring patients had a significantly higher mean of correct answers than their counterparts who reported referral of some painful episodes to orthodox health facilities (Ever referred: $9.83 \pm 5.43$ (41.0\%); Not ever referred: $10.22 \pm$ $5.54\{42.6 \%\} ; \mathrm{t}=-1.17, p=0.36)$ and consequently had a lower mean of incorrect answers than their counterparts who reported ever referral of some pediatric painful episodes to orthodox health facilities (Ever referred: $9.92 \pm$ $4.75\{41.3 \%\}$; Not ever referred: $9.64 \pm 4.15\{40.2 \%\} ; \mathrm{t}=$ $1.88, p=0.11$ ). Those who do not report ever referring a pediatric patient for pain-related conditions had a lower mean of unsure answers than their counterparts who do report ever referring such patients (Ever referred: $4.24 \pm$ $3.76\{17.7 \%\}$; Not ever referred: $4.12 \pm 3.79\{17.2 \%\}$; $\mathrm{t}=$ $0.82, p=0.42$ ).

CPs' responses were also evaluated in relation to their demographic profiles and some aspects of pediatric pain management. Results of ANOVA showed that 


\begin{tabular}{|c|c|c|c|c|c|c|c|c|c|c|}
\hline & & $\begin{array}{l}\dot{0} \\
0 \\
\dot{0} \\
\dot{0} \\
0 \\
0\end{array}$ & $\begin{array}{l}\hat{0} \\
0 \\
\text { î̀ } \\
\text { ô. } \\
0\end{array}$ & 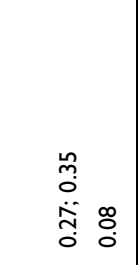 & $\begin{array}{l}\hat{o} \\
0 \\
\text { o. } \\
\text { o. } \\
0 \\
0\end{array}$ & 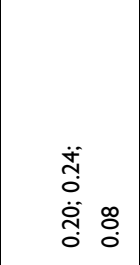 & o̊ & ¿̊. & $\stackrel{\circ}{\circ}$ & ̊̊. \\
\hline & & & & & & & $\begin{array}{l}\text { o. } \\
\stackrel{0}{0} \\
\text { i }\end{array}$ & 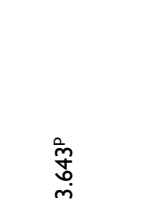 & \begin{tabular}{l}
$\hat{\sigma}$ \\
\multirow{\sigma}{\sigma}{} \\
$\dot{\sigma}$
\end{tabular} & $\begin{array}{l}\stackrel{\circ}{\mathrm{o}} \\
\stackrel{\text { o }}{\mathrm{m}}\end{array}$ \\
\hline & & 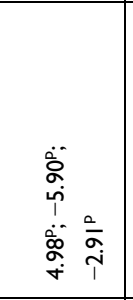 & 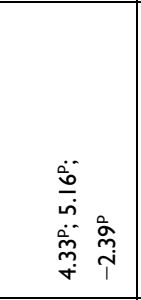 & 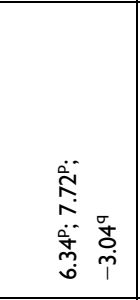 & 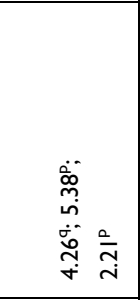 & 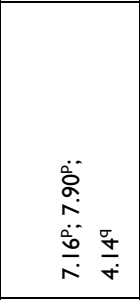 & & & & \\
\hline & 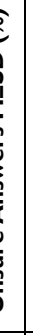 & 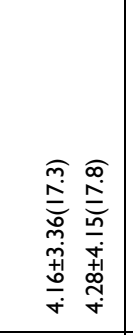 & 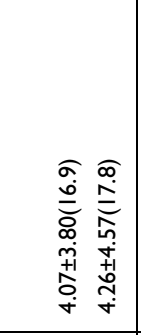 & 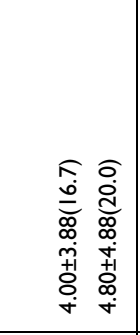 & 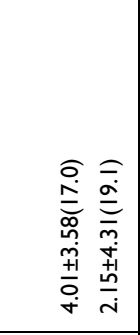 & 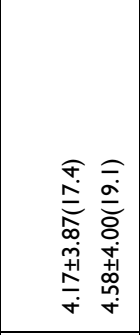 & 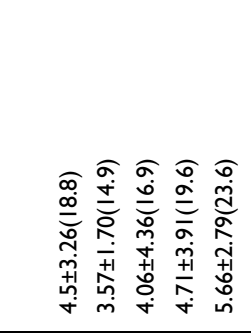 & 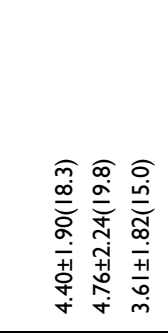 & 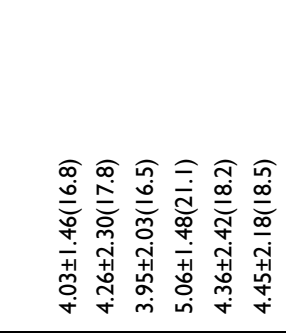 & 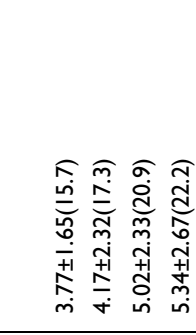 \\
\hline & 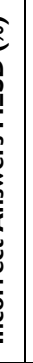 & 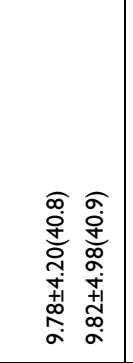 & 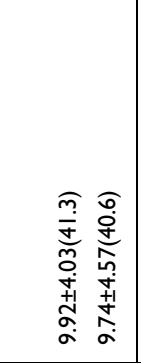 & 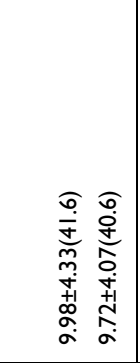 & 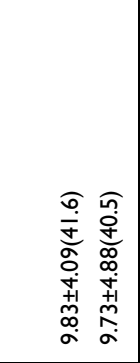 & 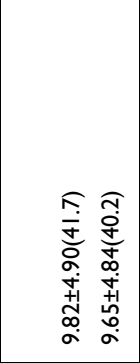 & 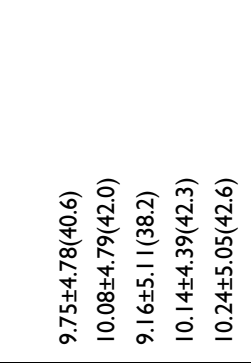 & 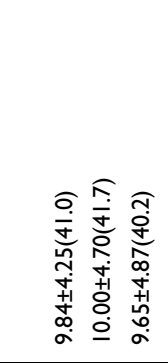 & 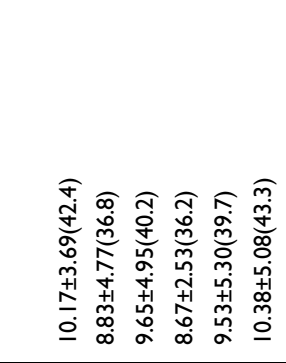 & 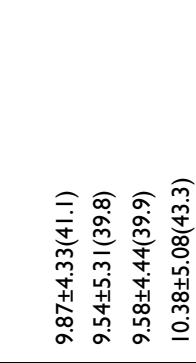 \\
\hline & & 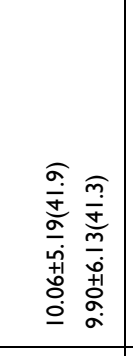 & 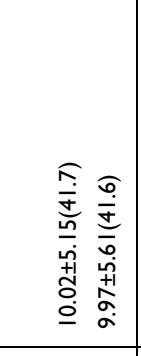 & 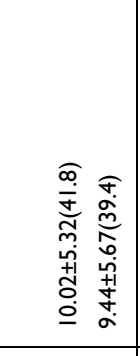 & 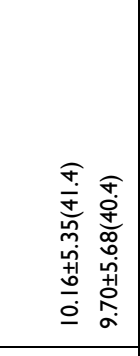 & 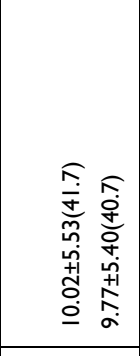 & 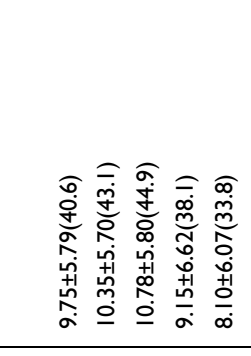 & 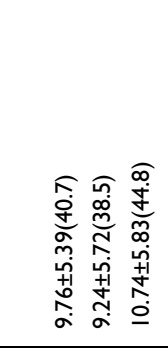 & 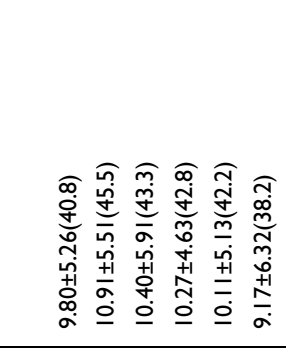 & 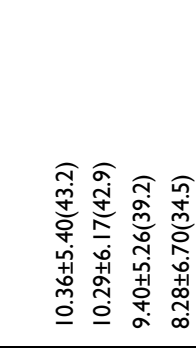 \\
\hline & & 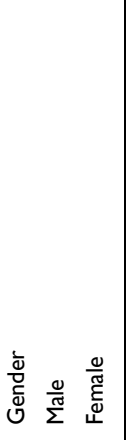 & 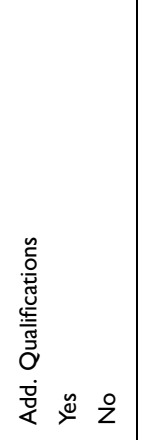 & 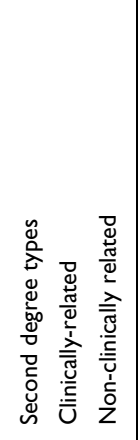 & 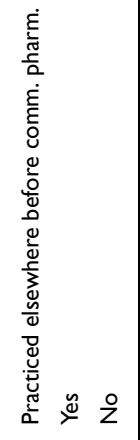 & 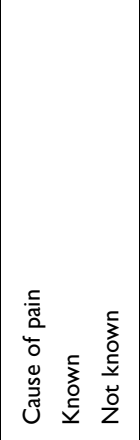 & 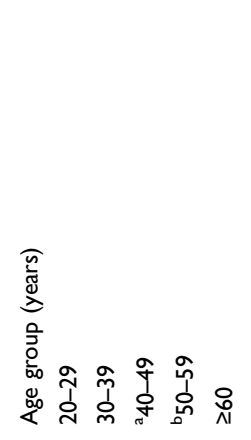 & 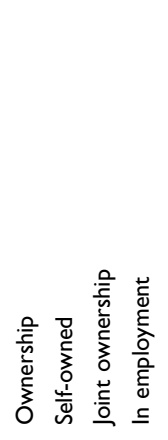 & 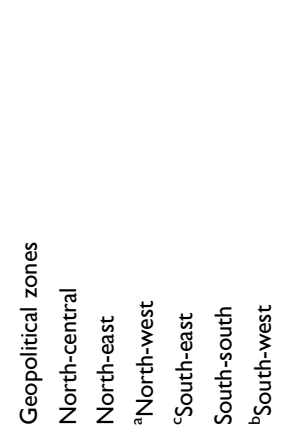 & 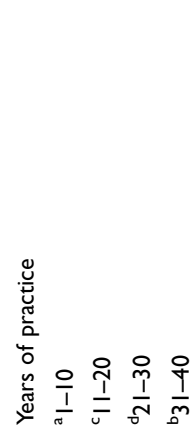 \\
\hline
\end{tabular}




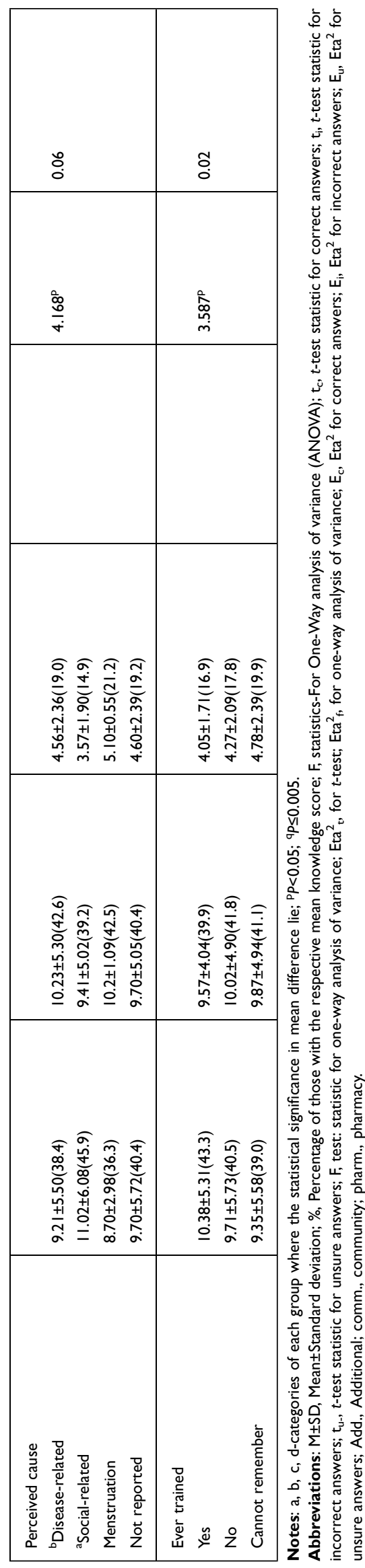

those in the 40-49 age group category had significantly higher mean correct answers relative to others $(10.78 \pm$ 5.80, $\mathrm{F}(4370)=2.858, p=0.025, \mathrm{Eta}^{2}=0.03$ ) (Table 3). Other components of the demographic profiles of the participants that produced significant differences in knowledge of pediatric pain management are participants' years of practicing community pharmacy, ownership structure of the premises, regional location of the premises, previous exposure to pain management training and perceived cause of painful episodes encountered (Table 3). However, there was no significant difference in knowledge of pediatric pain management based on years of qualification $\mathrm{F}(2372)=0.965$; $p=0.382$ ), despite those who qualified to practice pharmacy between 11 and 20 years ago $(\mathrm{M}=10.56 \pm 5.70)$ scoring the highest mean of correct answers, followed by those who qualified within a decade ago $(\mathrm{M}=10.22$ \pm 5.59). The type of career chosen before venturing into community pharmacy had no significant influence on CPs' knowledge of pediatric pain management. CPs who previously practiced in the hospital $(\mathrm{M}=10.50 \pm$ 5.40) had the highest mean correct answers; followed by those who have academic pharmacy experience, hospital and administrative pharmacy experiences $(\mathrm{M}=10.13 \pm 2.60)(\mathrm{F}(3251)=4.761, p=0.123)$. The number of previous pain management trainings attended by participants had no significant effect on their knowledge $(\mathrm{F}(2179)=0.565, p=0.569)$.

\section{Discussion}

This survey is probably the first to provide an insight into the knowledge of pediatric pain management among community pharmacists in a developing setting like Nigeria. Findings from the survey showed that CPs are a major primary healthcare provider that frequently attend to pediatric patients with various painful conditions and thus may contribute significantly to the effective management of pediatric pain in Nigeria. The outcome of the survey also revealed that participants answered two of every five questions on pain knowledge correctly and this significantly vary with age group, years of practicing community pharmacy, ownership structure of premises, geographical location of practice and previous exposure to pain management training.

Notwithstanding the general dearth of published studies on pediatric pain management among CPs, our finding is consistent that of Patel et al who reported inadequate knowledge of chronic pain among CPs. ${ }^{39}$ In addition, our 
finding is also consistent with the inadequate knowledge of the management of cancer-related pain reported among hospital pharmacists. ${ }^{16,19,36}$ Therefore, there is a clear need for regular audit of CPs' knowledge of the management of pediatric pain to identify relevant gaps, develop and implement appropriate interventions to improve the effectiveness of service delivery.

Our study finding showing that neck/shoulder pain was reported by CPs as the most commonly encountered among pediatric patients in practice is being reported for the first time. However, a recent Australian survey investigating CPs' views and practices of pain and fever management in the general population reported back pain to be the most commonly encountered. ${ }^{25}$ This contrast is apparently due to the difference in study population. This is because published reports of the location of pain experienced among children generally seemed to vary based on geographical location and data collection methods. ${ }^{5}$

Possession of clinically related additional qualification, including Pharm D and fellowship of West African Postgraduate College of Pharmacists, had the strongest relationship with higher knowledge of pediatric pain management among participants in the current survey. A similar finding has also been reported among hospital pharmacists delivering oncology services. ${ }^{37}$ Similarly, having practiced in other areas such as the hospital before commencing community pharmacy practice was associated with higher knowledge of pediatric pain management among the CPs sampled. This might probably be due to the impact of the pain management training provided by PFHI that trained over 11,000 HCPs including at least onetenth of the respondents in the current survey. Furthermore, previous training on pain management appeared to have had a positive impact on the CPs' knowledge of pediatric pain management in the current study. This finding is not surprising, as the role of educational intervention in improving pediatric pain knowledge of HCPs is well documented in published literature. ${ }^{52-55}$

Overall, CPs residing in Northeastern Nigeria had the highest mean correct answers. This interesting finding require further exploration as it is not really clear what factors may have accounted for the observed trend. This is because the pervasive insecurity in the Northeastern region of Nigeria has led to limited availability of HCPs and disruption of health systems which could interfere with knowledge acquisition, professional practice and optimal patient outcome. ${ }^{56,57}$ However, regional geographic differences in pain management knowledge have been reported generally among HCPs. ${ }^{36}$ In addition, physician opioid prescribing practices and pharmacists' concerns with stocking narcotics have also been reported to vary by regional geographic location. ${ }^{58,59}$ Another interesting finding in the current survey that require further exploration is that CPs who are employees had significantly higher knowledge scores relative to those who own their practice. It is probable that community pharmacist employees may have had additional training exposure and practice experience related to the management of pediatric pain and this may have been responsible for the higher mean knowledge scores observed among them.

It is noteworthy that, despite the CPs' correct answer to the item on codeine use (item 11) attracting more than the average score and higher than that reported by $\mathrm{He}$ et $\mathrm{al}^{60}$ seeking more information on codeine and opioids especially best practices regarding its handling from reliable sources is recommended. ${ }^{2,61-65}$ Codeine is a weak opioid that is no longer recommended for moderate pain in the pediatric population but rather low-dose morphine, ${ }^{26,66}$ and in fact its use in those less than 12 years old has been contraindicated. ${ }^{65}$

Like all studies, this survey is not without limitations and hence the findings reported should be interpreted in the light of limitations such as the use of nonprobability sampling method. However, the large size of the purposive sample of study participants was taken from the largest annual gathering of CPs from all the geopolitical zones in Nigeria, and this may have mitigated potential risk of wide variability and generalizability. Furthermore, recall and social desirability bias might have been introduced into the survey as most of the responses were from self-report. In addition, it is quite possible that majority of the respondents were those with interest or experience in pain management and this could have affected the findings reported. However, the development and use of a questionnaire with robust psychometric properties for data collection may have mitigated this and probably suggest that the findings reported are valid and robust. In addition, social desirability bias appeared not to have affected the findings as revealed by the low mean scores reported by community pharmacists for some of the items used for the assessment of knowledge of pediatric pain management. Furthermore, effect sizes were determined on significant findings to quantify the strength of relationship and association. 


\section{Conclusion}

Community pharmacists' knowledge of and attitude to pediatric pain management in Nigeria appeared suboptimal, and requires regular targeted educational intervention to fill the identified gaps, improve service delivery and patient outcomes. This could be achieved successfully through concerted efforts by all relevant stakeholders including the FMOH, Pharmacists Council of Nigeria, Pharmaceutical Society of Nigeria, Nigeria Association of Pharmacists in Academia and ACPN. Overall, community pharmacists' knowledge of pediatric pain management in Nigeria significantly vary by age group, years of practice, ownership structure, geographical location of practice and previous exposure to pain management training.

\section{Ethical Approval and Informed Consent}

The authors assert that all procedures contributing to this work comply with the Declarations of Helsinki and all other ethical standards of the relevant national guidelines on human experimentation. The study was approved by the Health Research and Ethics Committee of Usmanu Danfodiyo University Teaching Hospital, Sokoto with approval number: NHREC/30/012/2019. Informed consent of the study participants was individually sought (by requesting each participant to tick $(\sqrt{ })$ a Yes-box in the introductory page) and obtained after the nature and possible consequences of the study had been fully explained to them.

\section{Acknowledgments}

The authors are grateful to the following: the national executive committee, Education and Training committee, and conference planning committee and all members of the Association of Community Pharmacists of Nigeria who attended the 38TH Annual National Conference of the Association between 30th June, 2019 and 6th July, 2019 at Kano State, Nigeria. The national executive committee, Education and Training committee, and conference planning committee identified with the study and made access to attendees possible while attendees fully cooperated with us by providing data for the study.

\section{Disclosure}

The authors declare no conflicts or financial interest in any product or service mentioned in the manuscript, including grants, equipment, medications, employment, gifts, and honoraria. The authors had full access to all the data in the study and take responsibility for the integrity of the data and the accuracy of the data analysis.

\section{References}

1. International Association for the Study of Pain. Newsletter_revised definition of pain. Washington DC, USA; 2020. Available from: http://s3. amazonaws.com/rdcmsiasp/files/production/public/Revised $\%$ 20Definition\%20of\%20Pain_Translations.pdf. Accessed January 4, 2021.

2. World Health Organization. Guidelines on the Management of Chronic Pain in Children. Geneva, Switzerland: World Health Organization; 2020.

3. Goodman JE, McGrath PJ. The epidemiology of pain in children and adolescents: a review. PAIN. 1991;46(3):247-264. doi:10.1016/03043959(91)90108-A

4. Stanford EA, Chambers CT, Biesanz JC, Chen E. The frequency, trajectories and predictors of adolescent recurrent pain: a population-based approach. PAIN. 2008;138(1):11-21. doi:10.1016/ j.pain.2007.10.032

5. King S, Chambers CT, Huguet A, et al. The epidemiology of chronic pain in children and adolescents revisited: a systematic review. PAIN. 2011;152(12):2729-2738. doi:10.1016/j.pain.2011.07.016

6. Sleed M, Eccleston C, Beecham J, et al. The economic impact of chronic pain in adolescence: methodological considerations and a preliminary costs-of-illness study. PAIN. 2005;119(1-3):183-190. doi:10.1016/j.pain.2005.09.028

7. Groenewald CB, Essner BS, Wright D, et al. The economic costs of chronic pain among a cohort of treatment-seeking adolescents in the United States. J Pain. 2014;15(9):925-933. doi:10.1016/j. jpain.2014.06.002

8. Hahn KL. The roles of pharmacists in pain management. $J$ Pain Palliat Care. 2009;23(4):414.

9. Lalonde L, Leroux-Lapointe V, Choinière M, et al. Knowledge, attitudes and beliefs about chronic noncancer pain in primary care: a Canadian survey of physicians and pharmacists. Pain Res Manag. 2014;19(5):241-250. doi:10.1155/2014/760145

10. Tabeefar H, Chang F, Cooke M, Patel T. Community pharmacists and chronic pain: a qualitative study of experience, perception, and challenges. Can J Pain. 2020;4(3):29-39. doi:10.1080/ 24740527.2020.1749516

11. Birnie KA, Chambers CT, Fernandez CV, et al. Hospitalized children continue to report undertreated and preventable pain. Pain Res Manag. 2014;19(4):198-204. doi:10.1155/2014/614784

12. Stevens BJ, Harrison D, Rashotte J, et al. Pain assessment and intensity in hospitalized children in Canada. $J$ Pain. 2012;13 (9):857-865. doi:10.1016/j.jpain.2012.05.010

13. Friedrichsdorf SJ, Postier A, Eull D, et al. Pain outcomes in a us children's hospital: a prospective cross-sectional survey. Hosp Pediatr. 2015;5(1):18-26. doi:10.1542/hpeds.2014-0084

14. Walther-Larsen S, Pedersen MT, Friis SM, et al. Pain prevalence in hospitalized children: a prospective cross-sectional survey in four Danish university hospitals. Acta Anaesthesiol Scand. 2017;61 (3):328-337. doi:10.1111/aas. 12846

15. Ogunyinka IA, Oshikoya KA, Olowo-okere A, et al. Appropriateness of postoperative analgesic doses among pediatric surgical patients in a teaching hospital in Northwest Nigeria. Drug Therapy Perspect. 2019;35(3):135-144. doi:10.1007/s40267-019-00604-0

16. Furstenberg CT, Ahles TA, Whedon MB, et al. Knowledge and attitudes of health-care providers toward cancer pain management: a comparison of physicians, nurses, and pharmacists in the state of New Hampshire. J Pain Symptom Manag. 1998;15(6):335-349. doi:10.1016/S0885-3924(98)00023-2 
17. Jeon YS, Kim KK, Cleeland CS, Wang XS. Clinicians' practice and attitudes toward cancer pain management in Korea. Support Care Cancer. 2007;15(5):463-469. doi:10.1007/s00520-006-0183-x

18. Gagnon MM, Hadjistavropoulos T, Hampton AJD, Stinson J. A systematic review of knowledge translation (KT) in pediatric pain: focus on health care providers. Clin J Pain. 2015;32 (11):972-990. doi:10.1097/AJP.0000000000000345

19. Nuseir K, Kassab M, Almomani A. Healthcare providers' knowledge and current practice of pain assessment and management: how much progress have we made? Pain Res Manag. 2016;2016:8432973.

20. Peirce D, Corkish V, Lane M, Wilson S. Nurses' Knowledge and Attitudes Regarding Pediatric Pain Management in Western Australia. J Pain Manag Nur. 2018;19(6):707-717. doi:10.1016/j. pmn.2018.03.002

21. Adenekan TA, Owojuyigbe AM, Aaron OI, et al. Impact of pain management workshop on the knowledge and attitude of healthcare workers and opioid utilization in a Nigerian teaching hospital. W Afr $J$ Med. 2019;36(3):232-238.

22. Eke GK, Briggs DC. Management of paediatric pain: knowledge and practice of healthcare providers at a tertiary centre, Southern Nigeria. Asia J Pediatr Res. 2019;2(1):1-8.

23. Vagnoli L, Mammucari M, Daniela Graziani D, Messeri A. Doctors and nurses' knowledge and attitudes towards pediatric pain management: an exploratory survey in a children's hospital. J Pain Palliat Care Pharmacother. 2019;33:107-119. doi:10.1080/ 15360288.2019.1686100

24. Bond M, Acuna M, Barros N; other IASP members. Education and training for pain management in developing countries: a report by the IASP Developing Countries Taskforce. Seattle:IASP Press; 2007. Available from: www-iasp.pain.org/. Accessed January 3, 2021.

25. Mishriky J, Stupans I, Chan V. An investigation of the views and practices of Australian community pharmacists on pain and fever management and clinical guidelines. Pharm Pract. 2019;17(2):1436.

26. Federal Ministry of Health. Guidelines for the management of pain in Nigeria. Abuja, Nigeria; 2018. Available from: http://www.health. gov.ng/. Accessed January 3, 2021.

27. Perrot S, Cittee J, Louis $P$, et al. Self-medication in pain management: the state of the art of pharmacists' role for optimal Over- TheCounter analgesic use. Eur $J$ Pain. 2019;23:1747-1762. doi:10.1002/ejp.1459

28. Liossi C, Howard RF. Pediatric chronic pain: biopsychosocial assessment and formulation. Pediatrics. 2016;138(5):e20160331. doi:10.1542/peds.2016-0331

29. Williams G, Howard RF, Liossi C. Persistent postsurgical pain in children and young people: prediction, prevention, and management. PAIN Rep. 2017;2(5):e616. doi:10.1097/PR9.0000000000000616

30. Brattberg G. Do pain problems in young school children persist into early adulthood? A 13-year follow-up. Eur J Pain. 2004;8 (3):187-199. doi:10.1016/j.ejpain.2003.08.001

31. Hestbaek L, Leboeuf-Yde C, Kyvik KO, Manniche C. The course of low back pain from adolescence to adulthood: eight-year follow-up of 9600 twins. Spine (Phila Pa 1976). 2006;31(4):468-472. doi:10.1097/01.brs.0000199958.04073.d9

32. Taddio A, Chambers CT, Halperin SA, et al. Inadequate pain management during routine childhood immunizations: the nerve of it. Clin Ther. 2009;31(Supp12):S152-S167. doi:10.1016/j. clinthera.2009.07.022

33. Taddio A, Appleton M, Bortolussi R, et al. Reducing the pain of childhood vaccination: an evidence-based clinical practice guideline. Can Med Asso J. 2010;182(18):1989-1995. doi:10.1503/ cmaj.092048

34. Valeri BO, Ranger M, Chau CM, et al. Neonatal invasive procedures predict pain intensity at school age in children born very preterm. Clin J Pain. 2015;32(12):1086-1093. doi:10.1097/AJP.000000 0000000353
35. Victoria NC, Murphy AZ. Exposure to early life pain: long term consequences and contributing mechanisms. Curr Opin Behav Sci. 2016;7:61-68. doi:10.1016/j.cobeha.2015.11.015

36. Lebovits AH, Florence I, Bathina R, et al. Pain knowledge and attitudes of healthcare providers: practice characteristic differences. Clin J Pain. 1997;13(3):237-243. doi:10.1097/00002508199709000-00009

37. Xue YS, Czaplinski C, Harris D, McCorkle R, McCorkle R. Pain attitudes and knowledge among RNs, pharmacists and physicians on an inpatient oncology service. Clin J Oncol Nurs. 2007;11 (5):687-695. doi:10.1188/07.CJON.687-695

38. Silcock J, Moffett JK, Edmondson H, et al. Do community pharmacists have the attitudes and knowledge to support evidence based self-management of low back pain. BMC Musculoskeletal Disord. 2007;8:10. doi:10.1186/1471-2474-8-10

39. Patel T, Chang F, Mohammed HT, et al. Knowledge, perceptions and attitudes towards chronic pain and its management: a cross-sectional survey of frontline pharmacists in Ontario, Canada. PLoS One. 2016;11(6):e0157151. doi:10.1371/journal.pone.0157151

40. Oreagba IA, Ogunleye OJ, Olayemi SO. The knowledge, perceptions and practice of pharmacovigilance amongst community pharmacists in Lagos state, south west Nigeria. Pharmacoepidemiol Drug Saf. 2011;20(1):30-35. doi:10.1002/pds.2021

41. International Association for the Study of Pain (IASP). IASP curriculum on pain for pharmacy. Washington DC, USA; 2018. Available from: https//www.iasppain.org/Education/CurriculumDetail.aspx? ItemNumber $=2053$. Accessed January 4, 2021.

42. de Freitas GRM, de Castro CG, Castro SMJ, Heineck I. Degree of knowledge of health care professionals about pain management and use of opioids in pediatrics. Pain Med. 2014;15:807-819. doi:10.1111/pme. 12332

43. Hurley-Wallace A, Wood C, Franck LS, et al. Paediatric pain education for healthcare professionals. PAIN Rep. 2019;4(1):e701. doi:10.1097/PR9.0000000000000701

44. Kanabar D. A practical approach to the treatment of low-risk childhood fever. Drugs Res Dev. 2014;14:45-55.

45. Kanabar DJ. A clinical and safety review of paracetamol and ibuprofen in children. Inflammopharmacology. 2017;25(1):1-9. doi:10.1007/s10787-016-0302-3

46. Maurizio de M, Chiarugi A. Recent advances in pediatric use of oral paracetamol in fever and pain management. Pain Ther. 2015;4:149-168. doi:10.1007/s40122-015-0040-z

47. Fishman SM, Young HM, Arwood EL, et al. Core competencies for pain management: results of an interprofessional consensus summit. Pain Med. 2013;14(7):971-981. doi:10.1111/pme.12107

48. Manworren RCB. Development and testing of the Pediatric Nurses' Knowledge and Attitudes Survey Regarding Pain. Pediatr Nurs. 2001;27(2):151-158.

49. Alotaibi K, Higgins I, Chan S. Nurses' knowledge and attitude toward pediatric pain management: a cross-sectional study. $J$ Pain Manag Nur. 2017;20:118-125.

50. Cohen JW. The analysis of variance and covariance. In: Statistical Power Analysis for the Behavioural Sciences. Hillsdale, New Jersey: Lawrence Erlbaum Associates; 1988:284-287.

51. Ebel RL, Frisbie DA. Evaluating test and item characteristics. In: Essentials of Educational Measurement. Connaught Circus, New Delhi: Prentice-Hall of India; 1991:225-232.

52. Chiang L, Chen H, Huang L. Student nurses' knowledge, attitudes and self-efficacy of children's pain management: evaluation of an education program in Taiwan. J Pain Symptom Manag. 2006;32 (1):82-89. doi:10.1016/j.jpainsymman.2006.01.011

53. Le MS, Johnston CC, Choiniere M, et al. Pain management practices in a pediatric emergency room (PAMPER) study. Pediatr Emerg Care. 2009;25(8):498-503. doi:10.1097/PEC.0b013 e3181b0a0af 
54. Huth MM, Greggs TL, Lin L. Education changes Mexican nurses' knowledge and attitudes regarding pediatric pain. Pain Manag Nurs. 2010;11(4):201-208. doi:10.1016/j.pmn.2009.11.001

55. Van Hulle-vincent C, Wilkie DJ, Wang E. Pediatric nurses' beliefs and pain management practices: an intervention pilot. West $J$ Nurs Res. 2011;33(6):825-845. doi:10.1177/0193945910391681

56. Alloh FA, Regmi PR. Effect of economic and security challenges on the Nigerian health sector. Afr Health Sci. 2017;17(2):591-592. doi:10.4314/ahs.v17i2.37

57. Martineau T, McPake B, Theobald S, et al. Leaving no one behind: lessons on rebuilding health systems in conflict- and crisis-affected states. BMJ Glob Health. 2017;2(2):e000327. doi:10.1136/bmjgh-2017000327

58. Holdsworth MT, Raisch DW. Availability of narcotics and pharmacists' attitudes toward narcotic prescriptions for cancer patients. Ann Pharmacother. 1992;26(3):321-326. doi:10.1177/ 106002809202600302

59. Turk DC, Brody MC, Okifuji EA. Physicians' attitudes and practices regarding the long-term prescribing of opioids for non-cancer pain. PAIN. 1994;59(2):201-208. doi:10.1016/0304-3959(94) 90072-8

60. He T, Lardieri AB, Morgan JA. Pharmacist and pediatrician knowledge of codeine use in children. J Pediatr Pharmacol Ther. 2018;23 (4):293-297.
61. Federal Ministry of Health. National policy for controlled medicines and its implementation strategies. Abuja, Nigeria; 2017. https://www. unodc.org/documents/nigeria/Approved_National_Policy_For_ Controlled_Medicines_And_Its_Implementation_Strategies.pdf. Accessed January 3, 2021.

62. Hadland SE. How clinicians caring for youth can address the opioid-related overdose crisis. $J$ Adolesc Health. 2019;65 (2):177-180. doi:10.1016/j.jadohealth.2019.05.008

63. Hadland SE, Bagley SM. Opioid prescribing patterns and subsequent overdose. JAMA Pediatr. 2020;174(2):124-125. doi:10.1001/ jamapediatrics.2019.4885

64. Matson KL, Johnson PN, Tran V, Horton ER, Sterner-Allison J, Advocacy Committee on behalf of Pediatric Pharmacy Advocacy Group. Opioid use in children. J Pediatr Pharmacol Ther. 2019;24(1):72-75.

65. US Food and Drug Administration (FDA). FDA Drug Safety Communication: FDA restricts use of prescription codeine pain and cough medicine and tramadol pain medicines in children; recommends against use in breastfeeding women. New Hampshire Avenue, Silver Spring, MD; 2017. Available from: https:/www.fda. gov/Drugs/DrugSafety/ucm549679.htm. Accessed January 3, 2021.

66. World Health Organization. Pain ladder. Geneva, Switzerland; 2012. Available from: http:/www.who.int/cancer/palliative/painladder/en/. Accessed January 3, 2021.
Risk Management and Healthcare Policy

\section{Publish your work in this journal}

Risk Management and Healthcare Policy is an international, peerreviewed, open access journal focusing on all aspects of public health, policy, and preventative measures to promote good health and improve morbidity and mortality in the population. The journal welcomes submitted papers covering original research, basic science, clinical \& epidemiological studies, reviews and evaluations,

\section{Dovepress}

guidelines, expert opinion and commentary, case reports and extended reports. The manuscript management system is completely online and includes a very quick and fair peer-review system, which is all easy to use. Visit http://www.dovepress.com/testimonials.php to read real quotes from published authors. 